\title{
AGRICULTURA FAMILIAR: UM ESTUDO POLÍTICO NOS ASSENTAMENTOS RURAIS
}

\author{
FAMILY AGRICULTURE: A POLITICAL STUDY IN RURAL \\ SETTLEMENTS \\ GRANJA DE LA FAMILIA: UN ESTUDIO POLÍTICO EN LOS \\ ASENTAMIENTOS RURALES
}

\author{
Fabiano Greter Moreira \\ Universidade Federal de Mato Grosso do Sul/UFMS/CPNA \\ E-mail: fabiano.greter@ufms.br \\ Gabriel Moraes de Souza \\ Universidade Federal de Mato Grosso do Sul/UFMS/CPNA \\ E-mail: gabriellllsouzza@outlook.com
}

\begin{abstract}
Resumo: Com um crescimento elevado na população mundial um dos maiores desafios da humanidade é combater a fome com uma melhor alimentação, com isso os governos buscam cada vez mais o incentivo ao produtor melhorando sua produçáo e dando assistencia tambem no escoamento de todos os produtos com politicas voltadas ao agricultor. Leva-se também em conta a preservação do meio ambiente em que se está localizado, o universo da agricultura está bastante complexo em relação ao clima/região e tipos de vegetação em que se projeta sua produção. Busca-se com esta pesquisa bibliográfica, apresentar políticas públicas nos assentamentos rurais, bem como as formas de produção/renda na terra, e o avanço no setor produtivo no campo em seu tempo/espaço.
\end{abstract}

Palavras-chave: Assentados. Lote. Produção. Políticas públicas.

\begin{abstract}
With a high growth in the world population, one of humanity's greatest challenges is to fight hunger with better food, and governments are increasingly seeking to encourage producers by improving their production and by assisting in the sale of all products with targeted policies The farmer. It also takes into account the preservation of the environment in which it is located, the universe of agriculture is quite complex in relation to the climate / region and types of vegetation in which its production is projected. It seeks this
\end{abstract}


bibliographical research, present public policies in rural settlements, as well as the forms of production / income on land, and the advance in the productive sector in the field in its time/space.

Keywords: Seated. Lot. Production. Public policy.

Resumen: Con un alto crecimiento de la población mundial uno de los mayores retos de la humanidad es la lucha contra el hambre con mejor comida, por lo que los gobiernos buscan cada vez más el incentivo para los productores a mejorar su producción y dar ayuda también en el flujo de todos los productos con las políticas focalizadas el agricultor. También tiene en cuenta la preservación del medio ambiente en el que se encuentra, el universo agrícola es bastante complejo en relación con los tipos de clima / región y de la vegetación en la que se proyecta la producción. Buscar con esta literatura, para presentar las políticas públicas en los asentamientos rurales, así como las formas de producción / ingresos en la tierra, y los avances en el sector productivo en el campo en el tiempo / espacio.

Palabras clave: Abajo. Mucho. La producción. Políticas públicas.

\section{INTRODUÇÃO}

A produção capitalista provocou uma grande revolução no sistema agrário no Brasil. Buscando um maior aproveitamento das terras disponíveis e a geração de renda no campo, a competição entre pequeno produtor e latifundiarios é desigual, onde, as ações governamentais, em virtude dessas condições, promove oportunidades ao pequeno produtor fornecendo créditos rurais e melhorando as formas de produção e escoamento de seus produtos. Com isso, contribui na oferta de alimentos em uma determinada região, criando melhores condições de comercialização da produção, e também fomentando a economia e o desenvolvimento local.

Desde o inicio da civilização humana a agricultura ocupa um papel de importancia sobre a raça humana, desde o período pré-histórico o homem era predominantemente carnívoro uma vez que durante a era glacial e interglacial não havia vegetação no solo. Nesta época, o homem era caçador, alimentando-se de animais de grande porte e ao abater uma caça, compartilhava o alimento com o grupo, pois náo pensava no amanhá. Praticando a caça desde o paleolítico, o homem sobreviveu ao frio, pois a caça além de alimento lhe fornecia as peles para sua proteção, já no período Mesolítico, com o aquecimento do clima e o surgimento da vegetação, o homem além de caçador, passou a ser também coletor, o que lhe exigia a busca constante de alimentos em áreas distintas.

Estima-se que á cerca de 10 mil anos o homem iniciaria também o cultivo da terra e a domesticaçáo de animais, deixando de ser simplesmente um nômade caçador e coletor, para tornar-se agricultor e se fixar na terra. $\mathrm{O}$ início da agricultura está ligado a uma série de transformações que levaram ao aparecimento das sociedades históricas (ASSIS; ROMEIRO, 2002). 
O cultivo da terra juntamente com a fabricação de utensílios de cerâmica e de fornos, provocou a necessidade de estabelecer um núcleo habitacional fixo em torno dos campos cultivados. Desta forma, o homem passou de coletor a produtor de alimentos, fixando-se às margens de rios, onde lá encontravam clima essencial e terras ferteis ideal no cultivo de seus alimentos.

Carneiro (2005) destaca que praticamente em todas as culturas, os alimentos sempre foram relacionados com a saúde e que não apenas porque a sua abundância ou escassez colocam em questão a sobrevivência humana, mas também porque o tipo de alimentação a explicaçáo médica para a sua utilização sempre influenciaram a atitude de consumo diante da comida, considerando a sua adequação a certas idades, gênero, constituiçóes físicas ou enfermidades presentes.

Este trabalho busca apresentar uma visão ampla das políticas públicas, relacionadas à produção e os meios de comercialização da agricultura familiar no Brasil, por meio de um levantamento bibliográfico. Evidenciado em um estudo político, demonstrando a importância desta modalidade de incentivo na agricultura e na modernização do sistema de produção, de pequenos produtos, como forma de contribuir para a melhoria de seus rendimentos, mas, sobretudo, a permanência destes atores sociais no campo.

\section{CONTEXTUALIZAÇÃO DA AGRICULTURA NO BRASIL}

O cenário da agricultura é extremamente complexo e extenso, e composto de grande diversidade de vegetação, geográfico, clima, variáveis econômicas e sócias, etc., seja em virtude da existência de diferentes tipos de agricultores, os quais têm interesses particulares e culturas construidas ao longo de sua jornada no campo, planos próprios de sobrevivência e de produção, que respondem de maneira diferente a desafios e restriçóes em comuns.

Dentro desse cenário, a agricultura familiar destaca-se como uma forma de vida de milhares de homens e mulheres que resistem ao longo do tempo aos processos de políticas governamentais, e que buscam sobreviver dentro do mundo cada vez mais capitalista e, se manter em um ambiente competitivo, concorrendo em nível desigual com os grandes empreendimentos que atuam no setor do agronegócio.

De acordo com Instituto Nacional de Colonização e Reforma Agrária (INCRA, 2000) os vários tipos de produtores são portadores de racionalidades específicas que, ademais, se adaptam ao meio no qual estão inseridos, fato que reduz a validade de conclusóes derivadas puramente de uma racionalidade econômica única, universal e atemporal que, supostamente, caracterizaria o ser humano.

Este processo de formação da agricultura possui um contexto histórico de formação do Brasil rural junto ao processo de modernização da agricultura a partir da década de 1950, e mais recentemente os processos de globalização deflagrado nos anos 1990, tem trazido ao cenário atual mudanças nos padróes de funcionamento das unidades produtivas de base familiar, assim como a relação dessas unidades com aeconomia e com a sociedade. Essas mudanças apresentam-se para uma parte dos agricultores como forma de resistência ao 
processo de modernização e ao agronegócio, e para outros como uma forma de adaptação ao processo de globalização. Em ambos os casos, o processo proporciona aos agricultores uma permanência, ainda que precária, e sem recursos no campo.

A modernização da agricultura foi propagada no Brasil desde a metade do século XX, com o intuito de aumentar a produção e a produtividade de culturas de interesse internacional mediante a inserção de inovaçóes tecnológicas. Isto só foi possível no contexto de uma conjuntura política em que, o Estado foi o condutor, por meio de investimentos em pesquisas científicas, com a criação de órgáos como a Empresa Brasileira de Pesquisa Agropecuária (EMBRAPA), programas e créditos agrícolas.

De acordo com Mesquita (2009), a agricultura é gradativamente transformada em um setor de aplicaçáo de investimentos de capitais, representando um amplo mercado consumidor de insumos agrícolas e de bens de consumo, como fertilizantes e adubos, máquinas e equipamentos agrícolas, além, da indústria urbana e fornecedora de gêneros alimentícios e matérias-primas.

Este processo de modernização da agricultura no Brasil tem origem na década de 1950 com as importaçóes de meios de produção mais avançados, mas, no entanto, é na década de 1960, que esse processo ocorre de maneira concreta, com a implantação no país de um setor industrial voltado para a produçáo de equipamentos e insumos para a agricultura, iniciando a transformação da cadeia do agronegócio brasileiro.

Esta transformação buscava conduzir a agricultura tradicional, totalmente dependente da natureza e praticada por meio de técnicas rudimentares, para uma agricultura mecanizada e tecnológica na década de 1960. Marcando o início de um novo modelo de produção agrícola brasileiro, substituindo o chamado modelo de substituição de importaçóes, pela modernização do setor agrário e a formação do setor Agroindustrial (TEIXEIRA, 2005).

\section{PERSPECTIVAS DA AGRICULTURA FAMILIAR}

Caracteriza-se como agricultura familiar, o cultivo da terra realizado por pequenos proprietários rurais, tendo, como mão de obra, essencialmente, o núcleo familiar. Esta agricultura familiar aponta que, desde meados da década de 1990, vem ocorrendo um processo de reconhecimento e de criação de instituições de apoio a este modelo de agricultura. Além disso, foram criadas políticas públicas específicas de estímulo aos agricultores familiares, como o Programa Nacional de Fortalecimento da Agricultura Familiar - PRONAF (criado em 1995), as secretarias de governo orientadas exclusivamente para trabalhar com a categoria (como a Secretaria da Agricultura Familiar criada em 2003 no âmbito do Ministério do Desenvolvimento Agrário - MDA, criado em 1998).

Promulgou-se em 2006 a Lei da Agricultura Familiar, reconhecendo oficialmente a agricultura familiar como profissão no mundo do trabalho. Foram criadas novas organizaçóes de representação sindical com vistas a disputar e consolidar a identidade política de agricultor familiar (como a Federação Nacional dos Trabalhadores e Trabalhadoras na Agricultura Familiar - FETRAF). Além do mais, a elaboraçáo de um caderno especial sobre 
a Agricultura Familiar com os dados do Censo Agropecuário de 2006, contribuiu para evidenciar a importância social e econômica desta categoria de agricultores no país.

De acordo com a Lei no 11.326 de julho de 2006, considera-se agricultor familiar aquele que desenvolve atividades econômicas no meio rural e que atende alguns requisitos básicos, tais como: não possuir propriedade rural maior que 4 módulos fiscais; utilizar predominantemente mão de obra da própria família nas atividades econômicas da propriedade; e possuir a maior parte da renda familiar proveniente das atividades agropecuárias desenvolvidas no estabelecimento rural.

O módulo fiscal ${ }^{1}$ é uma unidade territorial agrária, fixado pelo INCRA à cada município brasileiro baseados na Lei Federal no 6.746/79. O tamanho do módulo fiscal, para cada município é determinado levando-se em consideração: o tipo de exploração predominante no município e a renda obtida com ela; outras exploraçóes importantes (seja pela renda ou área ocupada) existentes no município; e o conceito de "propriedade familiar", definido pela Lei $n^{\circ}$ 6.746/79. O módulo fiscal varia de 5 a 100 hectares, conforme o município.

No no ano de 2006, o IBGE realizou o Censo Agropecuário Brasileiro, a qual constatou-se a força e a importância da agricultura familiar para a produção de alimentos no país. Aproximadamente $84,4 \%$ dos estabelecimentos agropecuários do país são da agricultura familiar. Em termos absolutos, são 4,36 milhões de estabelecimentos agropecuários. Entretanto, a área ocupada pela agricultura familiar era de apenas 80,25 milhóes de hectares, o que corresponde a $24,3 \%$ da área total ocupada por estabelecimentos rurais.

\section{CARACTERIZAÇÃO DO ESTATUTO DA TERRA BRASILEIRO}

É a forma como se encontra formalizado o uso, ocupação e relações fundiárias no Brasil. No Brasil encontra se em LEI No 4.504, de 30 de Novembro 1964 em que fala conforme o Estatuto da Terra, criado em 1964, o Estado brasileiro tem a obrigação de garantir o direito ao acesso aterra para quem nela faz moradia e trabalha. No entanto, esse estatuto nem sempre é posto em vigor, visto que várias famílias lutam por seu direito de adquirir uma propriedade para trabalhar no campo.

Um dos primeiros códigos inteiramente elaborados pelo Governo Militar no Brasil, a Lei 4504, de 30 de novembro de 1964, foi concebida como forma de colocar um freio nos movimentos campesinos que se multiplicavam durante o Governo João Goulart.

Apesar de importantes peças para o ordenamento jurídico brasileiro, seu conteúdo é muito pouco difundido, e conta com poucos especialistas no meio doutrinário do assunto. Seus conceitos abarcam definições de cunho inteiramente político, servem para nortear as açôes de órgáos governamentais de fomento agrícola e de reforma agrária, como o INCRA, são diversos os conceitos ali enunciados, com importantes repercussões para a vida no campo, bem como a relação do proprietário de terras com o seu imóvel. Dentre elas está:

Reforma agrária - é o conjunto de medidas em que visem a promover melhor distribuição

1 Disponível em; <http://www.incra.gov.br/tamanho-propriedades-ruraisr $>$. Acesso em: 11 nov. 2016. 
da terra, mediante modificaçóes no regime de sua posse e uso, a fim de atender aos princípios de justiça social e ao aumento de produtividade.

Módulo rural - consiste, em linhas gerais, na menor unidade de terra onde uma família possa se sustentar ou, como define a lei: que absorva toda a força de trabalho, garantindo-lhes a subsistência e o progresso social e econômico - e cujas dimensóes, variáveis consoante diversos fatores (localização, tipo do solo, topografia, etc.), são determinadas por órgãos oficiais. Por estes critérios, uma área de várzea de meio hectare pode configurar, em tese, um módulo rural - ao passo que 10 hectares de caatinga podem não atingi-lo.

a) Minifúndio - Uma propriedade de terra cujas dimensões não perfazem o mínimo para configurar um módulo rural (nos exemplos anteriores, uma várzea de $0,2 \mathrm{ha}$ ).

b) Latifúndio - propriedades que excedam a 600 módulos rurais ou independentes deste valor, que sejam destinadas a fins não produtivos (como a especulação).

As funções estabelecidas pelo Estatuto da Terra estão pautados em dois eixos principais: a execução de uma reforma agrária e o desenvolvimento da agricultura. Cinco décadas depois, podemos notar que, a primeira meta ficou apenas no projeto, enquanto a segunda recebeu grande atenção, principalmente no que diz respeito sobre o desenvolvimento capitalista de produçáo na agricultura.

\section{CONTEXTO HISTÓRICO DOS PROJETOS DE ASSENTAMENTOS RURAIS}

Podemos compreender um assentamento rural como um conjunto de unidades agrícolas independentes entre si, instaladas pelo Instituto Nacional de Colonização e Reforma Agrária (INCRA), onde originalmente existia um imóvel rural (latifúndios) que pertencia a um único proprietário (Latifundiarios), cada uma dessas unidades, chamadas de parcelas, lotes ou glebas é entregue pelo INCRA a uma família sem condições econômicas para adquirir e manter um imóvel rural por outras vias.

A quantidade de glebas num assentamento depende da capacidade da terra em comportar e sustentar as famílias assentadas. O tamanho e a localização de cada lote são determinados pela geografia do terreno e pelas condiçóes produtivas que o local oferece. $\mathrm{O}$ funcionamento de um assentamento depende da própria máo de obra familiar, onde os assentados que recebem o lote comprometem-se morar em seus lotes e explorá-los para seu próprio sustento. Os assentados de reforma agrária, podem ter acesso a créditos fundiários, assistência técnica rural, infraestrutura e outros benefícios de apoio ao desenvolvimento das famílias assentadas. Até que possuam a escritura do lote, os assentados e a terra recebida estaráo vinculados ao INCRA, no entanto, sem ter posse da escritura do lote em seu nome, os assentado náo poderão vender, alugar, doar, arrendar ou emprestar sua terra a terceiros.

A questão agrária brasileira está intimamente ligada ao processo histórico de colonização do país. Desde os primórdios das capitanias hereditárias, passando pelos diversos ciclos econômicos (açúcar, mineração, café, pecuária, borracha, algodão etc.) até os dias atuais, a questão da posse da terra sempre esteve presente no cenário político nacional. Esse 
cenário foi fortemente agravado no período do pós-guerra quando o país implementou a política de "modernização da agricultura", ou seja um processo que provocou profundas transformações estruturais na esfera produtiva, mas que, ao mesmo tempo, causou sérias consequências sociais devido à enorme mobilidade populacional ocorrida nas últimas cinco décadas (MATTEI, 2013, p. 01).

Os assentamentos rurais são projetos criados pelo INCRA, que ao receber a posse do imóvel adquirido, é publicada a uma portaria criando o Projeto de Assentamento, onde constam os dados do imóvel, a capacidade estimada de famílias, o nome do projeto de assentamento e os próximos passos que serão dados para sua implantação. Os assentamentos rurais podem ser divididos em grupos:

a) PAs: São Projetos de Assentamento de Reforma Agrária criados por meio de obtenção de terras pelo INCRA, na forma tradicional.

b) PAE: os ambientalmente diferenciados denominados Projetam de Assentamento Agroextrativista.

c) PDS: Projeto de Desenvolvimento Sustentável.

d) PAF: Projeto de Assentamento Florestal.

Os Projetos de Assentamentos de reforma agrária são reconhecidos pelo INCRA, que possuem acesso às políticas públicas do Programa Nacional de Reforma Agrária (PNRA), que seguido de sua criaçáo, o INCRA inicia a fase de instalação das famílias no local, com o pagamento dos primeiros créditos e a realização do Plano de Desenvolvimento do Assentamento (PDA), responsável pela organização espacial do projeto.

Para Piccin (2015, p. 118-119):

"Dois aspectos são fundamentais para situar o campo, relativo aos produtores assentados, a primeira seria como a propriedade familiar se articula com o modo de produção capitalista e, a segunda, as características internas do grupo doméstico relacionadas com o trabalho e os recursos socioculturais. Tais aspectos remetem a um espaço de integração social em suas dimensóes política, cultural e econômica”.

As relaçóes encontradas nos assentamentos rurais em que os assentados se interagem, estão inseridas nas mais variadas estratégias de reprodução social e econômica no campo. Além disso, nesse espaço social, construído sócio-historicamente, os grupos de trabalhadores possuem características distintas um dous outros, como por exemplo, a "aptidão no campo". Contudo, o histórico dos aspectos que remetem a um espaço de integração social as famílias assentadas, que possuem sinergias distintas em suas dimensóes social, política, cultural e econômica no meio rural, criam novos territórios de reprodução social nestes ambientes, contribuindo para o desenvolvimento local/regional a qual estão inseridos. 


\section{MODERNIZAÇÃO DA AGRICULTURA E O DESAFIO DA SEGURANÇA} ALIMENTAR

A partir da década de 1960 iniciou-se um processo de modernizaçáo da agricultura brasileira. $\mathrm{O}$ impacto da modernização e suas consequências na atual dinâmica produtiva do país, sobretudo, o desenvolvimento sustentável, criou um grande debate teórico no paós. Neste processo de modernização, destaca-se em duas consequências: a primeira, relacionada aos impactos ambientais e, seus problemas mais frequentes, provocados pelo padráo de produção de monocultora como - a destruição das florestas e da biodiversidade genética, a erosão dos solos e a contaminaçáo dos recursos naturais e dos alimentos e; a segunda, contruídas a partir dos impactos socioeconômicos, causadas pelas transformaçóes rápidas e complexas da produção agrícola, implantadas no campo e os interesses dominantes do estilo de desenvolvimento capitalista de produção.

A expansão da agricultura "moderna" ocorre decorrente a constituição dos complexos agroindustriais, modernizando a base técnica dos meios de produção, alterando as formas de produção agrícola e gerando efeitos sobre o meio ambiente. As transformaçóes no campo ocorrem, porém, heterogeneamente, pois as políticas de desenvolvimento rural, inspiradas na "modernização da agricultura", são derivadas de desigualdades e privilégios (BALSAN, 2006).

Com um crescimento acelerado da população mundial esta cada vez mais difícil alimentar a todos, no centro do problema estáo à pobreza e a falta de poder, que impedem o acesso a alimentos nutritivos. Esta situação é agravada pela degradação constante dos solos, da água doce, dos oceanos e da biodiversidade.

Uma grande reforma do sistema de alimentação e de agricultura é necessária para garantir a segurança alimentar para cerca de um bilhão de pessoas que atualmente sofrem com a fome. Segundo dados da Organização das Naçóes Unidas - (ONU, 2014) o crescimento estimado da população e de dois bilhóes da população mundial até 2050.

Os agricultores que trabalham menos de dez hectares de terras representam cerca de um terço da população do mundo e uma grande maioria de pessoas em pobreza extrema. A agricultura é o maior empregador único, proporcionando meios de subsistência para 40\% da população global atual. É a maior fonte de renda e emprego para famílias rurais pobres.

O uso de insumos químicos artificiais e agrotóxicos para fins de aumento da produção, também atingiram indices elevados a partir da década de 1960. Segundo Graziano Neto (1985), entre 1965 e 1975 o consumo de fertilizantes cresceu a taxa média de $60 \%$ ao ano, enquanto que os agrotóxicos cresceram numa média anual de $25 \%$.

\section{PROGRAMAS SOCIAIS DE FORTALECIMENTO DA PRODUÇÃO NOS ASSENTAMENTOS RURAIS}

Atualmente, os assentamentos de reforma agrária ocupam um espaço crescente no debate social brasileiro devido ao potencial e à contribuição que estes agentes econômicos podem dar para criação de emprego e diminuição do êxodo rural, o aumento da oferta 
de alimentos, incrementos na produção agrícola e para a elevação do nível de renda e a consequente melhoria na qualidade de vida dos trabalhadores rurais brasileiros. Principal responsável pela comida que chega às mesas das famílias brasileiras, a agricultura familiar responde por cerca de $70 \%$ dos alimentos consumidos em todo o País. O agricultor familiar ganhou seu reconhecimento e já se comemora o dia internacional da Agricultura Familiar é comemorado dia 25 de julho com a consolidação dos avanços promovidos pelas políticas públicas integradas de fortalecimento do setor, intensificadas na última década.

De acordo com Ministério Desenvolvimento Agrário (MDA, 2015) o pequeno agricultor ocupa hoje papel decisivo na cadeia produtiva que abastece o mercado brasileiro com índices de: mandioca (87\%), feijão (70\%), carne suína (59\%), leite (58\%), carne de aves (50\%) e milho (46\%) são alguns grupos de alimentos com forte presença da agricultura familiar na produção.

Com melhores condições de crédito e a ampliação de mercado por meio de programas como o de aquisiçáo de alimentos, a agricultura familiar segue estruturada e com investimentos crescentes. O Plano Safra 2015/2016 da agricultura familiar recebeu um investimento recorde, mais de R \$ 28 bilhóes ao Programa Nacional de Fortalecimento da Agricultura Familiar (PRONAF).

Os recursos representam um aumento de $20 \%$ em relação à safra anterior. $\mathrm{Na}$ safra 2002/2003, o crédito disponível foi da ordem de R\$ 2,3 bilhóes. Na safra 2015/2016, o governo manteve baixas as taxas de juros, que variam entre $2 \%$ e 5,5\%. Para a região do Semiárido, os juros ficaram ainda menores, entre 2\% e 4,5\%. O plano prevê ainda que a Assistência Técnica e Extensão Rural (ATER) irão atender a 230 mil novas famílias de agricultores familiares, com foco na produção de base agroecológica.

Com uma visão de desenvolvimento na agricultura familiar o governo se propôs a adotar sistemas de credito ao produtor rural com incentivo a produçáo e comercialização beneficiando o produtor e a distribuição de alimentos sendo assim uma série de créditos rurais.

a) Programa Nacional de Fortalecimento da Agricultura Familiar (PRONAF): surgiu no ano de 1995 na qual o elevado custo e a escassez de crédito eram apontados como os problemas principais enfrentados pelos agricultores, em particular os familiares. Após 20 anos de execução não cabe nenhuma dúvida que o programa se estendeu de forma considerável por todo o território nacional, ampliou o montante financiado, desenvolveu programas especiais para atender diversas categorias, assumiu a assistência técnica e reforçou a infraestrutura tanto dos próprios agricultores como dos municípios em que se encontra (MDA, 2016).

Destina-se a estimular a geração de renda e melhorar o uso da mão de obra familiar, por meio do financiamento de atividades e serviços rurais agropecuários e não agropecuários desenvolvidos em estabelecimento rural ou em áreas comunitárias próximas.

b) AssistênciaTécnicaeExtensão Rural(ATER):éuma políticapúblicaquelevaassistência técnica às propriedades rurais. Melhora os processos no trabalho e, consequentemente, a 
qualidade de vida dos agricultores. As parcerias do MDA com instituiçóes públicas estaduais e privadas, principalmente aquelas sem fins lucrativos, garantem apoio ao produtor desde o início da safra até a colocação do produto no mercado as atividades de Ater são vinculadas à Política Nacional de Assistência Técnica e Extensão rural e buscam amplificar conhecimento e tecnologia com a finalidade de aumentar a produtividade e a renda, o acesso as políticas públicas da populaçáo rural brasileira, respeitando as diversidades sociais, econômicas, étnicas, culturais e ambientais do País (MDA, 2016).

c) Programa de Aquisiçáo de Alimentos (PAA): garante o atendimento de populaçóes em situaçáo de insegurança alimentar e nutricional e promove a inclusáo social no campo fortalecendo a agricultura familiar. Por meio do Programa, criado em 2003 e atualizado pela Lei no 12.512/2011, os órgãos públicos federais, estaduais e municipais podem adquirir os alimentos diretamente dos produtores. (MDA, 2016). A compra se dá mediante processo de dispensa de licitação. Os preços náo devem ultrapassar o valor dos praticados nos mercados locais. Produtos orgânicos ou agroecológicos admitem sobre preço de até 30\% (MDA, 2016).

d) Programa Nacional de Alimentaçáo Escolar (PNAE) prevê a compra de ao menos $30 \%$ dos alimentos provenientes da agricultura familiar para serem servidos nas escolas da rede pública de ensino. É alimento fresco e de qualidade na alimentaçáo escolar. É garantia de geração de renda para os agricultores e o município, dinamizando a economia local. A compra é feita por meio de chamadas públicas, com dispensa de licitação. O Programa possibilita a aquisição de alimentos da agricultura familiar e atua como ferramenta na garantia de segurança alimentar e nutricional, bem como para o desenvolvimento local (MDA, 2016).

e) Programa Nacional de Crédito Fundiário (PNCF): tem o intuito de facilitar o acesso a terra e aumentar a renda dos trabalhadores rurais é o objetivo desse programa. $\mathrm{O}$ PNCF financia a aquisição de imóveis rurais não passíveis de desapropriação. Ele também prevê Investimentos em infraestrutura básica, estruturaçáo da unidade produtiva e projetos comunitários de convivência com a seca no Semiárido e de recuperação ambiental. Quem acessa trabalhadoras e trabalhadores rurais sem-terra, jovens rurais ou agricultores com áreas insuficientes para a produção (minifundistas) (MDA, 2016).

f) Programa de Aceleraçáo do Crescimento (PAC2): o programa é a segunda etapa de um programa amplo do governo federal para grandes obras de infraestrutura no País, promovendo desenvolvimento social e econômico. Dentro do PAC, o MDA atua na entrega de retroescavadeiras e motoniveladoras, às prefeituras de municípios com até 50 mil habitantes não localizados em regióes metropolitanas. Além de caminhões-caçamba, caminhóes-pipa e pás-carregadeiras para o Semiárido. Com isso, o Programa promove melhor escoamento da produção dos agricultores familiares e mais desenvolvimento e qualidade de vida na área rural. (MDA, 2016).

g) Terra Forte: visa estimular e apoiar o incremento de renda nos projetos de assentamento por meio de atividades socioeconômicas sustentáveis, valorizando as características regionais, experiências e potencialidades locais. O programa destinará $\mathrm{R} \$ 600$ milhóes para financiamento dessas açóes até 2016. O recurso é destinado ao financiamento de projetos de cooperativas e associaçóes que visem à implantação e modernização de empreendimentos coletivos agroindustriais 
em assentamento da reforma agrária. Podem se inscrever entidades representantes de coletivos e associaçóes de famílias de trabalhadores rurais assentados pelo INCRA.

Apoiando agroindústrias, o programa busca aumentar a renda nos assentamentos da reforma agrária. São desenvolvidas atividades que valorizam as características regionais, experiências e potencialidades locais. Atividades não agrícolas, como turismo rural e artesanato, também são promovidos pelo Programa. É bom para o desenvolvimento do assentamento e também para a economia dos municípios, que ganhas em diversificação da produção e geração de renda. O suporte é dado por meio da elaboração de planos de negócios, pesquisas de mercado, consultorias, capacitação em viabilidade econômica, além de gestão e implantação, recuperação e ampliação de agroindústrias (MDA, 2016).

A comercialização da agricultura familiar se constitui como um grande desafio para a os assentados/produtores. O Governo Federal, preocupado com o tema, vem promovendo uma série de açóes para dinamizar a comercialização dos produtos oriundos da agricultura familiar, no sentido de superar os entraves, melhorando sua qualidade de vida, aumentando a renda dos agricultores, através da organização e capacitação dos produtores, contribuindo para a comercializaçáo de seus produtos.

De acordo com Saraiva et al. (2013), o apoio a estes agricultores como forma de estimular a produção de alimentos sustentáveis é considerado essencial, não só por sua capacidade de geração de ocupação e de renda, mas, como diversificar a oferta de alimentos de qualidade, com menor custo de transporte, propiciando maior confiabilidade no produto e, resgatando a preservação do hábito regional e da produção artesanal, conectados no campo e na cidade.

A Rede de Comercialização é uma estratégia de articulação entre as organizações de Assistência Técnica e Extensão Rural e a Secretaria da Agricultura Familiar do Ministério do Desenvolvimento Agrário. Tem como objetivo promover o intercâmbio de experiências no tema da promoçáo comercial dos produtos da agricultura familiar, bem como a disponibilização de subsídios na formulação e divulgação de programas e políticas públicas de comercialização, sobretudo o Programa de Aquisição de Alimentos - PAA. Além disso, visa à formação de agentes no tema da comercialização.

As principais ações da Rede de Comercialização dizem respeito ao PAA e suas modalidades, uma vez que este se constitui como principal programa de comercialização do Ministério do Desenvolvimento Agrário. Através da rede, podem ser demandados: capacitação para elaboração de projetos para acesso ao PAA, atividades (oficinas, reuniōes, seminários) de divulgação do programa, auxílio no acesso às modalidades do PAA, entre outras. As ações da rede direcionam-se, ainda, ao fortalecimento das iniciativas estaduais/locais que promovam o acesso dos agricultores familiares ao mercado (MDA, 2015).

Atualmente, o valor repassado pela União a estados e municípios por dia letivo para cada aluno é definido de acordo com a etapa e modalidade de ensino, o repasse é feito diretamente aos estados e municípios, com base no Censo Escolar realizado no ano anterior ao do atendimento. O PNAE é acompanhado e fiscalizado diretamente pela sociedade, por meio dos Conselhos de Alimentaçáo Escolar (CAE), pelo FNDE, pelo Tribunal de Contas da Uniāo (TCU), pela Controladoria Geral da União (CGU) e pelo Ministério Público. 
De acordo com dados obtidos do Portal FNDE estima se um orçamento do Programa para 2015 de R \$ 3,8 bilhôes, para beneficiar 42,6 milhóes de estudantes da educação básica e de jovens e adultos. Com a Lei no 11.947 , de 16/6/2009, 30\% desse valor - ou seja, R $\$ 1,14$ bilhão - deve ser investido na compra direta de produtos da agricultura familiar, medida que estimula o desenvolvimento econômico e sustentável das comunidades (MDA, 2015).

De acordo com Schröetter (2012, p. 02) “a aquisição desses produtos, além de qualificar a alimentação servida na merenda escolar, viabiliza a manutenção e apropriação de hábitos alimentares saudáveis, respeitando a cultura, às tradiçóes e ainda amplia o desenvolvimento de forma sustentável”.

Com o crescimento da classe média global, aumenta também o consumo de alimentos, colocando pressões crescentes sobre os sistemas agrícolas. Esforços estão em andamento para reduzir o desperdício na produção e distribuição de alimentos e para promover métodos agrícolas que reduzam as emissóes de gases-estufa, além de outros impactos ambientais negativos da agricultura, como a perda de solos férteis e poluição da água. Melhores hábitos alimentares devem ser estimulados nos países ricos, que têm uma ingestão calórica insustentável e desproporcionalmente alta. Em muitos países pobres, a ajuda deve ser direcionada para as populaçóes onde a agricultura está sob maior risco.

As consideraçôes sobre reforma agrária e agricultura familiar no Brasil vem, desde os anos 40, sendo associadas a outros temas, sobretudo às consequências a ela relacionadas ou atribuídas, como desenvolvimento econômico nacional e regional, redução da fome e pobreza, distribuição de renda, justiça, meio ambiente, cidadania, etc. Mais recentemente, implementação de programas de reforma agrária vem também sendo analisada enquanto componente da noção de segurança alimentar (NORDER, 1998, p. 02).

Consequência de uma série de fatores, a demanda por alimentos vem crescendo no Brasil e, de acordo com estimativas, os produtos necessários, como arroz e feijão, devem ter o crescimento do consumo associado ao aumento da população (BRASIL, 2015). Essa demanda tem crescido por volta de $1 \%$ ao ano, pouco abaixo do crescimento populacional do país. No entanto, outros produtos com maior valor agregado (alimentos industrializados), que são procurados em virtude do melhor poder aquisitivo da populaçáo brasileira, alavancaram as vendas nos últimos cinco anos. Entre eles estáo: carne de frango, com alta de $1,87 \%$ ao ano (a.a.); carne bovina, 2,77\% a.a.; leite de vaca, 2,29 a.a.; iogurte, 2,97\% a.a.; azeite, 3,06\% a.a.; e queijo, 3,52\% a.a. Entre as bebidas, destaque para a cerveja $(3,85 \%$ a.a.), vinho (3,2\% a.a.) e cachaça $(2,11 \%$ a.a. $)$.

Segundo o MDA (2017), agricultores familiares brasileiros contrataram, na safra 2015/2016, mais de R \$ 22 bilhóes de crédito para financiar a produção junto ao Banco do Brasil. O Plano Safra em seus mais de 20 anos de existência destinou R \$ 160 bilhóes em crédito e; 27 milhóes de contratos realizados em todo país e, com uma inadimplência abaixo de 1\%. Entre as principais novidades do Plano Safra da Agricultura Familiar 2016/2017, está a redução dos juros de 5,5\% para 2,5\% aos agricultores que produzem alimentos que compóem a cesta básica do povo brasileiro, tais como, arroz, feijão, café, batata e trigo. 
Também se encaixam nessas condições a apicultura, a piscicultura e a criação de ovinos e caprinos MDA (2017).

O Plano Safra disponibilizado pelo Banco do Brasil na safra atual é 10\% maior do que o ofertado no ano agrícola anterior. Dos $\mathrm{R} \$ 101$ bilhóes de recursos, $\mathrm{R}$ \$ 91 bilhóes serão voltados ao crédito rural a produtores e cooperativas e R $\$ 10$ bilhóes serão destinados a empresas em cadeia do agronegócio. $\mathrm{O}$ volume de recursos para a agricultura familiar cresceu $8 \%$ em relaçáo à safra passada, quando o valor foi de $\mathrm{R} \$ 13,5$ bilhóes. Além do Banco do Brasil, o agricultor familiar pode apresentar o projeto de crédito a outras 17 instituições financeiras MDA (2017).

\section{PERCURSO METODOLÓGICO}

O trabalho utilizou-se o método científico com aporte na técnica em pesquisa bibliográfica, que para Gil (2008), pode-se definir pesquisa como processo de desenvolvimento do método científico e o objetivo principal da pesquisa é descobrir respostas para inquisições mediante o levantamento de dados e pesquisas científicas.

A pesquisa bibliográfica, ou de fontes secundárias, abrange toda bibliografia já tornada pública em relação ao tema de estudo, sua finalidade é colocar o pesquisador em contato direto com tudo o que foi escrito, dito ou filmado sobre determinado assunto, inclusive conferências seguidas de debates que tenham sido transcritos por alguma forma, quer publicadas, quer gravadas. Dessa forma, a pesquisa bibliográfica não é mera repetiçẫo do que já foi dito ou escrito sobre certo assunto, mas propicia o exame de um tema sob novo enfoque ou abordagem, chegando a conclusóes inovadoras (MARCONI; LAKATOS, 2003, p. 183).

Contudo conclui-se que o conjunto de dados e informaçóes levantados através de artigos científicos, de bases governamentais, como o IBGE, o MDA, o INCRA, enfim, auxiliaram nos conceitos e no desenvolvimento teórico do trabalho, apresentando os diversos programas e políticas públicas para o desenvolvimento econômico e social dos assentamentos rurais no Brasil, bem como, suas várias alternativas de créditos financeiros e assistência técnica rural aos projetos de reforma agrária no país.

\section{CONSIDERAÇÓES FINAIS}

Com o crescimento da produção da agricultura familiar temos um cenário de vários incentivos ao pequeno produtor, por meio de políticas públicas que estimulam a produção e também a comercialização dos seus produtos. Este trabalho teve como objetivo apresentar uma visão de como vem ocorrendo os meios de assistência à produção e também comercialização da agricultura familiar no Brasil. Através de um estudo político, apresentamos os programas sociais e políticas públicas dirigidas aos agricultores familiares, por meio, de linhas de créditos e formas de comercialização de sua produção, promovendo melhores condiçóes de sua permanência no campo. 
Com um intenso processo de modernização da agricultura, o estudo trouxe um levantamento bibliográfico de políticas públicas já implantadas, que buscam dar sustentabilidade aos moldes de reforma agrária praticados no Brasil, e também especificamente aos projetos de assentamentos rurais, em atendimento ao disposto dos regimentos governamentais da agricultura familiar, a qual estes produtores/assentados estáo direcionados socioeconomicamente.

Vários são as diretrizes e modalidades de atendimento ao que chamam de reforma agrária, porém, devem-se ainda, promover políticas públicas que busquem uma maneira de incluir todos os assentados-produtores, de maneira econômica, social, política e cultural, sobretudo, um resgate do homem do campo, e suas potencialidades na produção de alimentos e sua identidade pela terra de trabalho.

A agricultura familiar busca como papel social, a diminuição do êxodo rural e no combate a desigualdade social no campo e nas cidades. Promove uma melhor qualidade de vida aos assentados, e ainda, contribuem para a produçáo de alimentos, em meio, a crescente estimativa populacional mundial. Contudo, a Agricultura Familiar deve ser encarada pela sua capacidade de geração de riqueza e de desenvolvimento, não apenas para o setor agropecuário, mas, o resgate dos atores sociais envolvidos nesta categoria, sobretudo, o papel social e econômico para o país..

\section{REFERÊNCIAS BIBLIOGRÁFICAS}

ASSIS, R. L.; ROMEIRO, A. R.. Agroecologia e agricultura orgânica: controvérsias e tendências. Desenvolvimento e meio ambiente, v. 6, p. 67-80, 2002.

BALSAN, R.. Impactos decorrentes da modernização da agricultura brasileira1/decurrent impacts of the agriculture modernization in brazil. Campo-Território: revista de geografia agrária, v. 1, n. 2, 2006.

BRASIL. Lei no 11.326, de 24 de julho de 2006. Estabelece as diretrizes para formulação da política nacional da agricultura familiar e empreendimentos familiares rurais. Presidência da República. Brasília/DF, 2006. Disponível em:<http:/www.planalto.gov.br/ccivil_03/_ ato2004-2006/2006/lei/l11326.htm.>. Acesso em: 11 nov. 2016.

BRASIL. Lei no 6.746, de 10 de Dezembro de 1979. Altera o disposto nos arts. 49 e 50 da Lei no 4.504, de 30 de novembro de 1964 (Estatuto da Terra), e dá outras providências. Brasília/DF, 197. Disponível em:<http://www.planalto.gov.br/ccivil_03/leis/1970-1979/ L6746.htm>. Acesso em: 01set. 2017.

BRASIL, Agricultura familiar produz $\mathbf{7 0} \%$ dos alimentos consumidos por brasileiro. Disponível em: <http://www.brasil.gov.br/economia-e emprego/2015/07/agricultura-familiar-produz-70-dos-alimentos-consumidos-por-brasileiro>. Acesso em: 11 nov. 2016.

BRASIL, Crescimento da renda aumenta demanda por alimentos. Disponível em: $<$ http://www.brasil.gov.br/economia-e-emprego/2013/10/crescimento-da-renda-aumenta-demanda-por-alimentos>. Acesso em: 11 nov. 2016. 
CARNEIRO, H. S. Comida e sociedade: significados sociais na história da alimentação. História: questóes \& debates, v. 42, n. 1, 2005.

Congresso Nacional Brasileiro, LEI No 4.504, de 30 de novembro de 1964. Disponível em; <http://www.planalto.gov.br/ccivil_03/leis/L4504.htm>. Acesso em: 11 nov. 2016.

INCRA/FAO. Novo retrato da agricultura familiar: o Brasil redescoberto. Brasília: INCRA/FAO, 2000. Disponível em: < http://www.incra.gov.br/>. Acesso em: 08 nov. 2016.

GIL, A. C. Métodos e Técnicas de Pesquisa Social. 60 edição. São Paulo, Editora Atlas S. A., 2008, p. 220.

GRAZIANO NETO, F. Questão Agrária e Ecologia: Crítica da Agricultura Moderna, São Paulo: Brasiliense, 1985.

IBGE, Instituto Brasileiro de Geografia e Estatística. Censo Agropecuário 2006. Disponível em: <http://www.ibge.gov.br/home/estatistica/economia/agropecuaria/censoagro/>. Acesso em: 11 nov. 2016.

INCRA, Instituto Nacional de Colonização e Reforma Agrária. Classificaçáo Imóveis Rurais. Disponível em:<http://www.incra.gov.br/tamanho-propriedades-rurais $>$. Acesso em: 11 nov. 2016.

INCRA, Instituto nacional colonização e reforma agrária. Projetos de reforma agrária. Disponível em:<http://www.incra.gov.br/sites/default/files/uploads/reforma-agraria/questao-agraria/reforma-agraria/pa_2015.pdf>. Acesso em: 14 dez. 2016.

MARCONI, M. A.; LAKATOS, E. M. Fundamentos de Metodologia Científica. $5^{\mathrm{a}}$ edição. São Paulo, Editora Atlas S. A., 2003, p. 310.

MESQUITA, L. A. P.; MENDES, E. P. P. Modernização da agricultura e formação dos complexos agroindustriais. XIX Encontro Nacional de Geografia Agrária, São Paulo, p. $1-17,2009$.

MATTEI, L.A reforma agrária brasileira: evolução do número de famílias assentadas no período pós-redemocratização do país. Estudos Sociedade e Agricultura, v. 2, 2013.

MDA, Ministério do Desenvolvimento Agrário. Políticas públicas para a agricultura familiar. Disponível em: <http://www.mda.gov.br/sitemda/sites/sitemda/files/ceazinepdf/ politicas_publicas_baixa.pdf>. Acesso em: 14 dez. 2016.

MDA, Ministério do Desenvolvimento Agrário. A força da agricultura familiar. Disponível em:<http://www.mda.gov.br/sitemda/noticias/for\%C3\%A7a-da-agricultura-familiar $>$. Acesso em: 14 dez. 2016.

MDA, Ministério do Desenvolvimento Agrário. Agricultores familiares contrataram R\$ 22,1 bilhóes do Pronaf na safra 2015/2016. Disponível em: <http:/www.mda.gov.br/ sitemda/noticias/agricultores-familiares-contrataram-r-221-bilh\%C3\%B5es-do-pronaf-na-safra-20152016>. Acesso em: 14 dez. 2016.

NORDER, L. A. C. A construção da segurança alimentar em assentamentos rurais: questôes, contextos e métodos. Cadernos de debate, v. 6, p. 40-58, 1998. 
ONU, Organizaçôes das Naçôes Unidas. A ONU e a população mundial. Disponível em: <https://nacoesunidas.org/acao/populacao-mundial/>. Acesso em: 01set. 2017.

PICCIN, M. B. Assentamentos rurais e geração de renda: posição social restringida, recursos socioculturais e mercados. Economia e sociedade, v. 21, n. 1, p. 115-141, 2015.

SARAIVA, E. B. et al. Panorama da compra de alimentos da agricultura familiar para o Programa Nacional de Alimentação Escolar. Cien Saude Colet, v. 18, n. 4, p. 927-936, 2013.

SCHRÖETTER, M. R. A agricultura familiar e o consumo de alimentos na merenda escolar: o caso da Regiáo Fronteira Noroeste. Monografia, Unijuí, Santa Rosa - SC, 2012. TEIXEIRA, J. C. Modernização da agricultura no Brasil: impactos econômicos, sociais e ambientais. Revista Eletrônica AGB-TL, v. 1, n. 2, p. 21-42, 2005.

Recebido para publicação em maio de 2017

Aceito para publicação em janeiro de 2018 